\title{
The Development and Comparative Analysis of Engineering Project Management Modes
}

\begin{abstract}
Engineering project management is the whole process of project construction management activities up to the point of achieving the goals of engineering construction, which adopts the means of planning, organizing, leading, and controlling. In addition, engineering project management modes are the works of project management and the technical guarantee of project success. For the quality and efficient transformation demands of the Chinese construction industry in the process of marketization, internationalization and informatization, based on the connotation and development path of engineering project management modes, the 16 main and new kinds of project management modes both domestically and abroad are divided into trading mode, financing mode and management mode. These have led to comparative analysis and brief commentary. Finally, it will be pointed out that the engineering project management modes move throughout the whole management process, the combined model and the expansion development of financing model. This work will provide reference for project participants to choose the appropriate project management modes and better understand building company transformation.
\end{abstract}

Keywords: engineering projects, management mode, comparative analysis, development trend

\section{Introduction}

With China's deepening accession to the WTO (World Trade Organization) and the reformation of engineering construction management systems, China's projects have

Manuscript received July 9, 2015; accepted November 2, 2015

Ji-wei Zhu (ه), Li-nan Zhou, Ming-yuan Yu

School of Civil Engineering and Architecture, Xi'an University of

Technology, Xi'an, 710048, China

Email: zhujiwei@xaut.edu.cn

Zhao Zhai

Research Institute of Complex Engineering\&Management, Tongji University, Shanghai, 200092, China become larger, more complicated and more international. Project investment is diversification (Wan, 2012). China's construction industry is facing a great number of opportunities and challenges. It is in the transformation stage, which is from the management based on specialized divisions to whole process integrated management. With the advantages of technology and management innovation, financing ability, business level and integrated service ability, large engineering project contractors from developed countries are to the fore of the international construction market. At present, the domestic construction market is excessively competitive, and its volatility risk is high. Double pressures at home and abroad have an impact on China's construction industry and improving the comprehensive competitiveness of building companies is imminent. Engineering project management mode is a key to the success of construction projects, whether an appropriate mode is chosen or not will directly affect the achievement of construction goals (Joslin \& Muller, 2015). The Chinese construction industry should actively absorb and study the international advanced management concept and mode based on China's conditions. Domestic research of management modes focuses on the following several aspects. Zhuo-fu Wang advocated that the construction project transaction mode should be innovated based on the status quo of application (Wang, He, \& Hong, 2008). Zhang (2008) put forward the use of portfolio project management modes according to different sections and characteristics of practical engineering. Zhao-han Sheng pointed out that taking advantage of large complex project integrated management mode solves complex engineering problems (Sheng, You, \& Li, 2008).

Based on the above views, this article explores the development course and connotation of engineering project management, reviews and combs through 16 kinds of engineering project management modes at home and abroad, points out the developing trend of engineering project management mode through comparative analysis of them, and provides support for Chinese construction companies to choose the appropriate project management mode and discern the means of transformation better. 


\section{Connotation and status of the development of project management mode}

\subsection{Connotation of project management mode}

Project management, which is also called construction engineering project management, refers to a process which people use methods to plan and control construction projects to carry out the cost, progress and quality targets as effectively and efficiently as possible over the course of the project's lifecycle (Le, 2013).

Engineering project management model is the application and practice of project management knowledge in construction projects. It is the comprehensive operation method and the mode of organization and management that project construction companies use various related resources and measures to ensure the achievement of construction goals over the course of the project's lifecycle. Engineering project management mode clears the responsibility and obligation of all interests subject and determines the overall framework of the project management and governance structure. It is the integration of project management knowledge and management mechanism (Wang \& Jian, 2006). Its primary core goal is proving project value scientifically and reasonably.

\subsection{Development of project management mode}

In a specific historical period and economic environment, engineering project management mode is innovating and developing constantly with the transfer of management centers. The initial project management pattern originated in the late 1770 s, at a time when most construction projects were simple, construction technology and project management level was relatively backward and enterprises mainly used "design-construction-operation" mode. The owner signed a contract for the design and construction and carried out the project management independently. Up to the early 1790 s, due to the improvement of economic level and a large number of infrastructure constructions, the U.S. government took the lead in trying to push DBB (the Design-Bid-Build) on government investment projects and introduced project consulting to project management areas. Construction general contracting mode was produced and developed rapidly at the same time. In the $1860 \mathrm{~s}$, Partnering pattern, which was first used in Britain, changed the traditional form of project management organization. Its application greatly improved the relationships between various project participants.

In the late 1950s, the United States put forward the Critical Path Method (CPM) and Program Evaluation and Review Technique (PERT) on project management, and successfully applied them to the Apollo Moon Program and Polaris Missile Project. Project management developed substantially. In the 1970s, the CM (Construction Management) model began to gain traction and was widely used on construction sites to shorten the construction period. These marked professional construction management services have been used in the construction field. From the 1980 s to the mid-1990s, engineering project management mode developed systematically, scientifically and diversely according to different targets. In order to adapt to economic globalization, the typical EPC (Engineering-Procurement-Construction) and DB (DesignBuild) model were produced to solve the divorce between design and construction. In addition, new urbanization developed rapidly during this period. The financing models such as BOT (Build-Operate-Transfer) and ABS (AssetBacked-Securitization) were used widely with the purpose of importing private capital to speed up the establishment of national public utilities. From the late 1990s up to the 21 st century, with the rapid development of the construction industry, international cooperation on construction projects increased. Construction projects encountered many political, social, economic, and environmental protection challenges and uncertainty increased incessantly. The complexity of projects was also increasing. Management technology in different domains was used interactively. The new theory and new technologies were applied to the large and complex constructions. New Management mode such as PMC (Project-ManagementContract) and total project control were developed and spread gradually. In this period engineering project management mode went into the diversified parallel development stage.

\section{Comparative analysis of engineering project management patterns}

Because of variety of the popular project management modes, they need to be classified. Zhuo-fu Wang divided engineering project management modes into financing pattern and trading pattern (Wang \& Jian, 2006). Hui An, Chuan-jun Zheng summarized major international project management mode and divided them into the traditional mode, engineering general contracting mode, the project management contract mode and others (An \& Zheng, 2013). Based on the above views, according to different management emphasis, this article extends the connotation of engineering project management mode to three forms. These are the transaction mode, the financing mode and the management mode. In the transaction mode, owners pay more attention to the project's entity construction and the delivery of the finished product, such as the process of project feasibility study, design, construction, installation, commissioning and so on. The financing model focuses on solving the problem of capital projects funds. The management mode is the way that the owner chooses the professional management team for entity production and finance management. The three forms are complementary relationships which complement each other rather than 
either or alternative relationships.

\subsection{The trading mode}

Zhuo-fu Wang thinks that the trading patterns refer to the way of trading activity between different subjects and the economic legal relationship they form in the construction market (Wang, He, \& Hong, 2008). Trading pattern in this section mainly refers to the delivery mode of project entity in the course of the construction. This part chooses several typical trading patterns such as DBB, EPC mode amongst others to analyze. The partnering mode is a special one; it cannot be used alone, but is generally combined with trading patterns. Thus it is put into comparative analysis. Detailed comparison is shown in Table 1.

Through the comparison and analysis, the general contracting modes such as the DB and EPC have obvious advantages in terms of cost, schedule, cohesion of design and construction compared with the DBB mode. However, they all use Lump Sum Contract. The risk is bigger than the DBB mode, which uses the Unit Price Contract. The DB and EPC mode reduces the quantities of management and coordination of owners. At the same time, it will affect quality control due to the low degree of intervention. The NC mode compared with others has a special advantage in so far as it can not only ensure the overall requirements of the owners but can also realize the integration of design and construction. The partnering mode puts emphasis upon communication and information sharing. When applied, it reduces disputes between the investors and the other partners.

\subsection{The financing mode}

The goal of financing mode is raise funds, includes forms of financing organization, sources of financing, terms of capital recovery, etc. This mode has a connection with the strength, financial credit and target among others of the project sponsors. In April 2014, the Standing Committee of the State Council decided to encourage and attract social capital to participate in the construction and operation of projects in the form of joint ventures, wholly owned and franchising in accordance with the deployment of the Government Work Report. This report was applicable to railways, ports, other transportation infrastructure, a new generation of information infrastructure, major hydropower, wind power and other clean energy projects among others (The Chinese State Development and Reform Commission, 2015).

This decision shows that the development of the financing mode is of great urgency with the development of the country's public affairs at the present stage. There are diverse forms of financing modes according to different sources of finance. We select classic financing modes such as the BOT and BT modes and financing modes which are widely used at present such as the PPP mode to compare and analyze. Detailed comparison is shown in the Table 2.

The financing modes above aim at reducing the pressure on government finances. The BOT mode has a long history and is widely used. The BT is the derivation of the BOT, and the difference between the BT and BOT modes is that contractors do not participate in the operation. This difference shortens the time and repayment periods of projects and is beneficial to government since it can easily count and control the return on investment. Compared with the BOT projects which are always given up halfway through, the BT projects run stably and are increasing constantly in China. At the end of 2014, the China Railway Construction Corporation raised about $¥ 10$ bn to invest in BT projects (Gao, 2014, December 18). The TOT mode is different to other financing modes. Since the government transfers a certain amount of land property rights and management rights, it has no construction risk. The PFI mode emphasizes effective public services whereas other modes focus on the ownership of the final project. The ABS mode in reducing financing cost is superior to the others. The generalized PPP pattern includes the BOT and TOT modes and is mainly used in construction of infrastructure and public utilities and other social public utilities. It also emphasizes private-public cooperation, risk-sharing and the value of project for money audit.

\subsection{The management mode}

The management mode refers to the way that the project owner chooses a professional management team to provide the whole process or some phase of the project management services in order to ensure the achievement of the project goals (An \& Zheng, 2013). It can be divided into the independent management mode, the entrusted management mode and the agent construction mode. The independent management mode requires the owner to have a high management level, and it is difficult to manage and coordinate. Nowadays it is less frequently applied, so this section mainly compares typical modes of latter two types, such as the PMC mode and the CM mode. Detailed comparison is shown in the Table 3.

Through the comparison of Table 3 , it is shown that the $\mathrm{CM}$ mode has obvious advantages in terms of shortening the construction period. The DM mode pays attention to providing the owners with the design and construction management. The PMC and Agent Construction System focus on commercial demonstration and management services which are provided by management contractors throughout the whole process of the project from preplanning to project implementation. It can make full use of project management technology systems and integrate project resources, achieve the maximum economic benefit of the project. The PC unit of the PC mode is not directly involved in the project management, but it uses modern information technology to provide investors with strategy consulting. Nowadays, the PC mode needs to be used in 


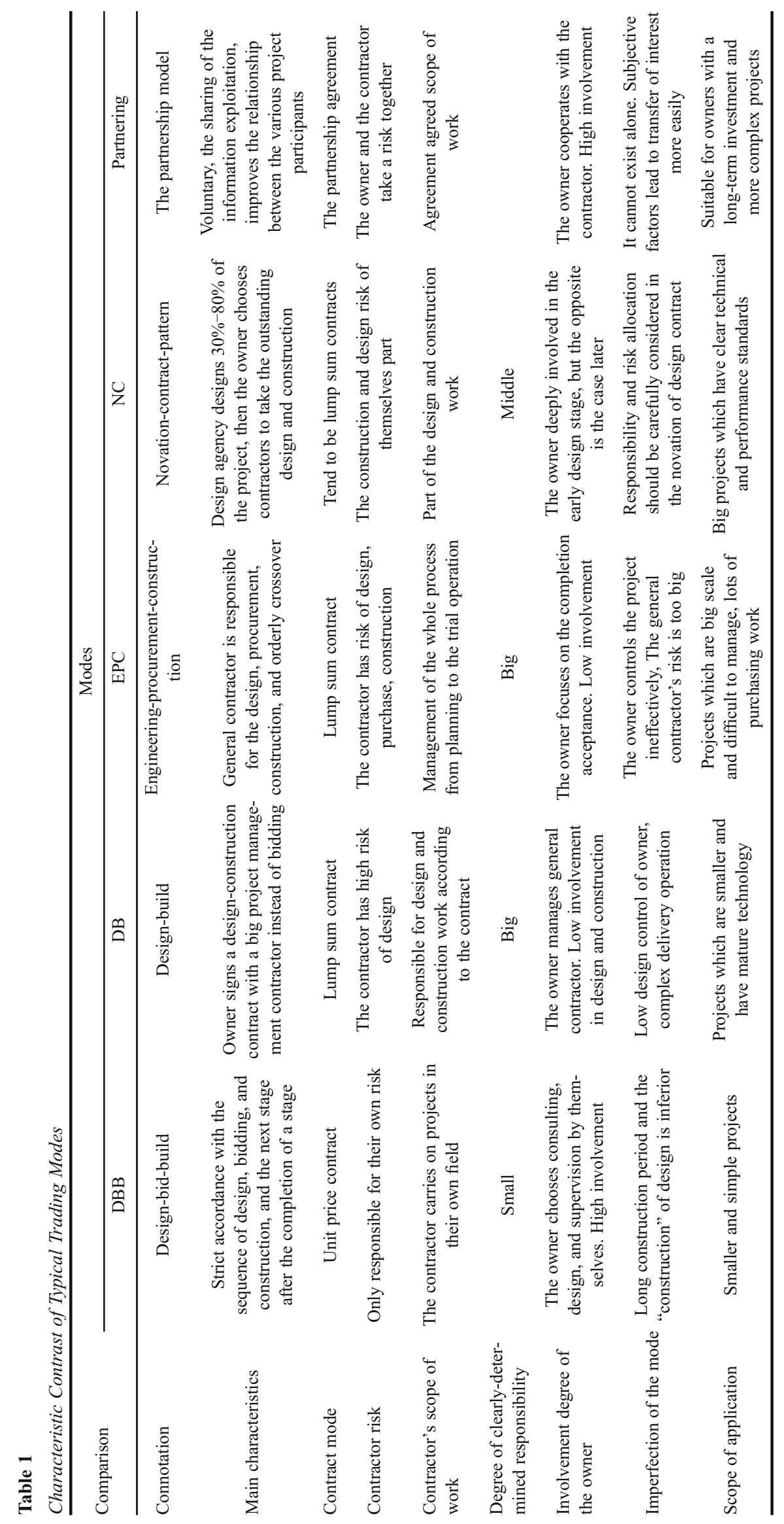


conjunction with other project management modes.

\section{Development trend of engineering project management mode}

Through the illustration of the development course and comprehensive comparison of project management modes, combined with the construction industry market environment at home and abroad, this paper summarizes that Chinese engineering project management mode is heading towards the following three trends:

(1) The whole process of project management

At present, the domestic construction industry market competition is intense. The process of Chinese construction industry internationalization is growing at an ever-increasing rate. However, compared with mature project management companies in developed countries, Chinese companies placed a great deal of emphasis on qualifications and specialization division in the past so that cannot meet the requirements of the comprehensive working of international project design, procurement, construction and others. This can be seen from the development and contrast of engineering project management mode. Engineering project management has developed from the traditional professional management according to the division of professional tasks to the integration of design and construction management, and also from the sections of entrusted management to the whole process of the entrusted management. For example, the Shanghai Expo project adopted the integrated control of project management methods (Le \& Jiang, 2010). The five key technologies are proposed to develop and to innovate project management methods.

This development reflects the owner's demand for professional management after the role transition in the process of engineering construction management system reform. It is also the inevitable developing trend of modern engineering project management.

(2) The model application portfolio

The application combination mode has two forms. The first form is that some special management modes such as the partnering mode and the ABS mode which cannot be used alone must combine with another kind of specific project management mode for project operation. The second form is crossing two or more project management modes to foster strengths and circumvent weaknesses in the construction of the project in order to solve the practical problems such as complications, the huge scale of the project, the owners' mistrust of general contractors and so on. For example, in order to reduce the cost, the South-toNorth Water Diversion Project was led by the Project Legal Person, and a new mode which combined with direct management, mandatory administration and Agent Construction System management mode according to the characteristics of the engineering construction was used
(Zhang, 2008). Another example is the highway from Chishui (Guizhou) to Wangmo area on the Anshun to Ziyun section for which the mode of BOT + EPC + government subsidies was adopted to invest in its construction.

(3) Expanded financing model application

With the acceleration of the urbanization process, a large number of infrastructure projects need to be built on time. The construction funds of infrastructure mainly rely on land grant and borrowings from banks. These ways lead to the shortage of local government funding and increased debt (Cheng, Cai, Yang, \& Wang, 2015). Therefore, the infrastructure financing system must implement the market-oriented development. According to the State Council's guidance, social capital is considered to the weak link in areas such as water affairs, rail transportation, energy and so on to participate in the reform in public medical institutions (The Chinese State Council, 2014). It also encourages the government, society and enterprise capital to jointly promote the new urbanization and national infrastructure construction based on franchising, by the private sector operating public buildings and by private sector construction with government support. The PPP, the BT and so on are not only kinds of financing modes, but they are also approaches which can help to improve the productivity of the construction of utilities. The government should transform their roles and change the way of management to avoid and cope with possible risk (Wang \& Feng, 2015). The functions of investors, operators and supervisors are separated to improve the efficiency of public construction and complete the change of government function.

\section{Conclusions}

A wide view of the development process of engineering project management modes, from the fine division of professional management to the whole process of integrated planning, design, procurement and construction management mode is the international development trend. Many elements such as development in the field of construction, reform project construction management systems and the change of financial market and so on promote the development and innovation of the project management mode.

In the realistic environment in China, the construction industry is facing a transformation and Chinese construction companies should simultaneously receive and raise their international competitive power, and incorporate foreign advanced project management pattern according to Chinese national conditions, thus forming the engineering project management mode with Chinese characteristics. The PPP, agent, EPC etc. project management modes should be actively promoted and achieve localization. In the tide of internationalization, Chinese construction 


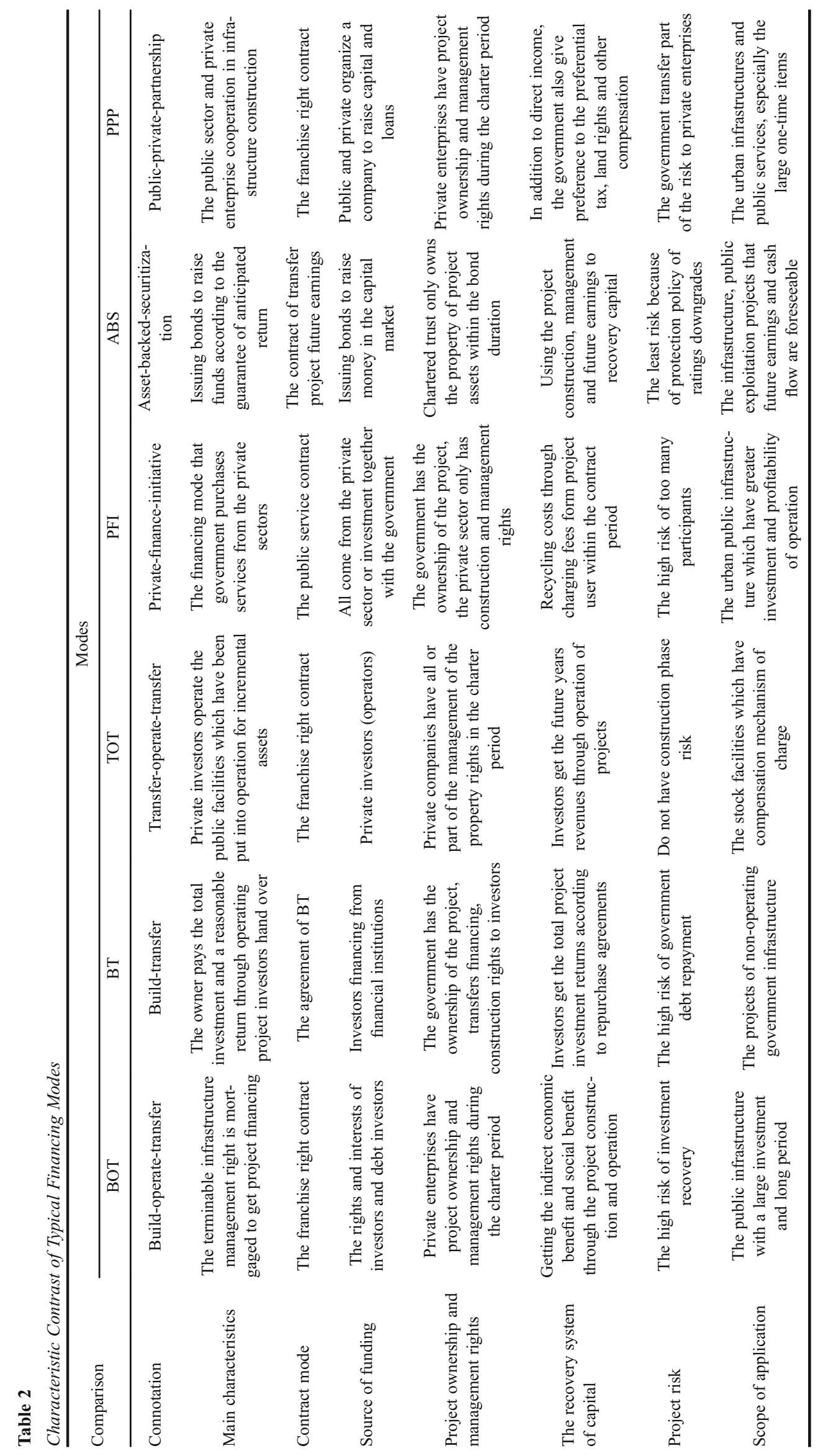




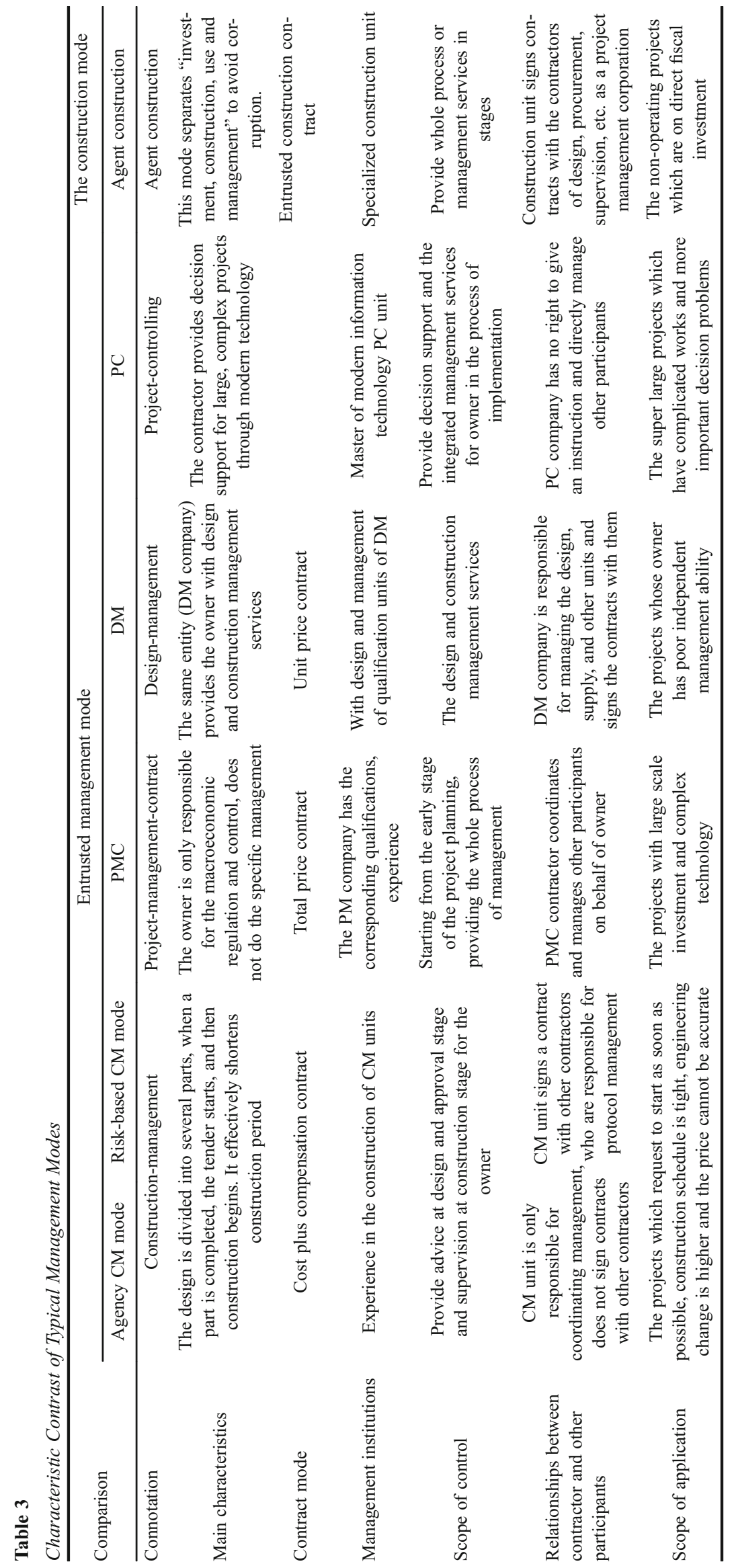


companies should complete comprehensive and integrated enterprise reform together with the government, industry, and speed up the development of China's "opening up" strategy.

\section{References}

An, H., \& Zheng, C. (2013). Analysis of project management mode and its evolvement mechanism. Journal of Engineering Management, 27, 97-101

Cheng, Z., Cai, J., Yang, Z., \& Wang, S. (2015). Research on the framework of financing planning in the process of China's urbanization. Journal of Engineering Management, 29, 37-42

Gao, J. (2014, December 18). The financing advantage is obviously, Chinese Railroad Construction Company raises about ten billion input the BT projects. The 21st Business Herald

Joslin, R., \& Muller, R. (2015). Relationships between a project management methodology and project success in different project governance contexts. International Journal of Project Management, $33,1377-1392$

Le, Y. (2013). Construction project management (p.13). Beijing: Science $\&$ Technology Press

Le, Y., \& Jiang, W. (2010). The five key technologies of large and complex group project systemic control-Development and innovation of the project management method. Project Management
Technology, 08, 19-24

Sheng, Z., You, Q., \& Li, Q. (2008). Methodology and method of large scale complex engineering management: meta-synthesis management. Science \& Technology Progress and Policy, 10, 193-197

The Chinese State Council. (2014). The State Council's guidance of encouraging to introduce social investment to investment and financing mechanism in areas of innovation emphasis (State issues, No. 2014 60). Beijing: The Chinese State Council

The Chinese State Development and Reform Commission. (2015). The Chinese State development and reform commission issued the government and social capital cooperation promotion projects. Beijing: The Chinese State Development and Reform Commission

Wan, D. (2012). Research on construction project integrated management model based on life-cycle management. China Civil Engineering Journal, S2, 267-271

Wang, S., \& Feng, K. (2015). Calm and think in the upsurge of PPP mode. Urban and Rural Development, 08, 38-40

Wang, Z., He, L., \& Hong, W. (2008). Investigation and study of the Chinese project construction transaction mode development. Construction Economy, 02, 59-63

Wang, Z., \& Jian, Y. (2006). Engineering project management mode and its innovation. Beijing: China Water \& Power Press

Zhang, J. (2008). The exploration and practice of construction management system in South-North Water Transfer Project (pp. 81-89). Beijing: China Water \& Power Press 